\title{
Newborn Care Practices in Rural Communities of Nawalparasi District, Nepal
}

\author{
${ }^{1}$ Hari Prasad Kaphle, ${ }^{1}$ Dipendra Kumar Yadav, ${ }^{2}$ Nirmala Neupane, ${ }^{3}$ Bimala Sharma, \\ ${ }^{1}$ Dilip Kumar Yadav, ${ }^{4}$ Samjhana Kumari Poudel \\ ${ }^{1}$ School of Health and Allied Sciences, Pokhara University, Lekhnath-12, Kaski, Nepal \\ ${ }^{2}$ Masood College of Nursing, Rajiv Gandhi University of Health Sciences, Bangalore-564001, Karnataka, India \\ ${ }^{3}$ Gandaki Medical College, Lekhnath, Kaski, Nepal \\ ${ }^{4}$ Chitwan School of Medicine, Bharatpur, Chitwan, Nepal.
}

\begin{abstract}
Most of the new born deaths in the developing countries occur due to lack of access to care, as majority of the deliveries occur at home. Even deliveries conducted in health facilities are prone to suffering from traditional care practice after discharge from health facilities. Most of these deaths could be avoided with changes in antenatal, delivery and newborn care practices. This study was conducted to explore the newborn care practices related to cord care, thermal care and breast feeding in rural setting and to identify socio-demographic, antenatal and delivery care factors associated with these practices. A cross sectional study in rural setting of Nawalparasi district included 296 women who had delivered live baby at home or discharged within 24 hours of delivery from hospital proceeding four months of data collection. Chi squire test was applied to compare sociodemographic, antenatal and delivery care factors associated with cord care, thermal care and breast feeding practices. Of the total 296 mother interviewed, only 65.54\% have completed ANC visit at least 4 times and $29.05 \%$ have received counselling on newborn care during pregnancy. More than half deliveries (53.38\%) were home deliveries and Clean Home Delivery Kit was used only one third (39.91\%) of these deliveries. Of the three selected newborn care practices, clean cord keeping practice was found in only one fourth (25.70\%) of deliveries. However early initiation of breast feeding and delayed bathing practice was found in about half of the deliveries (51.35\% and $58.45 \%$ respectively). There is strong need to implement the community-based interventions to improve the new born care practices in community level and to reduce the high-risk newborn care practices like unsafe cord care, delayed breast feeding, early bathing, prelacteal feeding and discarding colostrum need through the community level health workers and volunteers.
\end{abstract}

Key words: Newborn care, Safe cord care, Early breast feeding, Thermal care, Delayed bathing.

Corresponding address: Hari Prasad Kaphle, School of Health and Allied Sciences, Lekhnath-12, Kaski, Nepal. E-mail: harikafle07@gmail.com

\section{INTRODUCTION}

A silent epidemic occurring in developing countries that no one is assuming as an epidemic is the high neonatal mortality. Of the approximately four million global neonatal deaths that occur annually, 98\% occur in developing countries, where most newborns die at home while they are cared by mothers, relatives and traditional birth attendants. Even deliveries conducted in health facilities by the trained birth attendances are prone to suffering from harmful traditional care practices after discharge from health facilities. ${ }^{1}$

Globally under five mortality rates have declined significantly over past four decades, but high neonatal mortality rate has remained relatively unchanged. ${ }^{2-4}$ About $2 / 3^{\text {rd }}$ of all infant deaths and $38 \%$ of all under five deaths occur during neonatal period. Two third of these neonatal deaths occur during first week of life and $2 / 3^{\text {rd }}$ of these deaths occur within first 24 hours of born. The primary causes of neonatal deaths are believed to be the complication of prematurity (28\%), sepsis and pneumonia (26\%), birth aspexia and injuries (23\%), tetanus $(7 \%)$ and diarrhea $(3 \%)$, with low birth weight contributing to a large number of deaths. ${ }^{1,3,5}$
In Nepal, there has been a massive reduction in child mortality rates last few years. The under five-mortality rate has declined from 118 per 1,000 live births to 61 per 1,000 live births from 1996 to 2006 . The infant mortality rate has also declined from 79 per 1,000 live births to 48 per 1,000 live births in same period. Similarly in 2006-2010 period under five mortality rate has declined from 79 per 1000 live births to 54 per 1000 live births and infant mortality has also declined from 48 per 1000 live births to 46 per thousand live births. Overall, reduction these indicators confirm improvements in the status of child health. However, the Neonatal Mortality Rate (NMR) has scantly declining rate. In 1996, NMR was 39 per 1,000 live births and in 2006 it was 33 per 1,000 live births and still 33 per 1000 live births in $2011 . .^{6-8}$ Data suggest that the major causes of neonatal death in Nepal are infection, birth asphyxia, preterm birth and hypothermia.

Although 58\% of mothers received antenatal care from Safe Birth Attendances (SBAs) for their most recent birth, only $36 \%$ of babies are delivered by these SBAs and $28 \%$ are delivered at a health facility indicating that Nepal has a long 
way to go to meet the Millennium Development Goals target of $60 \%$ births attended by a skilled provider. However, it is encouraging to note that the proportion of babies attended by skilled provider over the last five years has nearly doubled, from $19 \%$ in 2006 to $36 \%$, while the proportion of babies delivered in a health facility has increased from $18 \%$ in 2006 to $28 \% .^{7-9}$ Early childbearing, poor maternal nutrition, micro nutrient deficiencies, inadequate access and utilization of quality care during pregnancy, delivery and in the post partum period, are the fundamental factors for low status of women and newborns in Nepal. ${ }^{10}$

According to World Health Organization (WHO) implementation strategies, there is now consensus on a set of proven interventions that can save newborn lives. However, it will not be possible to introduce and sustain the whole package on a large scale at one time. Since newborn health status, infrastructure and available resources vary among and within countries, scenario based approaches will be required for program planning. In low resource settings, strategies can be phased so that more feasible interventions are introduced first, such as tetanus immunization, drying and warming and immediate breastfeeding and more complex interventions like resuscitation by bag and mask are taken up incrementally as the scenario improves. The WHO has given guidelines for essential newborn care which include the hygiene during delivery, keeping the newborn warm, early initiation of breast-feeding, exclusive breast-feeding, care of the eyes, care during illness, immunization and care of low birthweight newborns. Therefore, it is necessary for the mother and her family to understand these aspects of childbirth and newborn care and be prepared to react for the potential dangers signs. ${ }^{11,12}$

The objective of this study was to examine the selected newborn care practices related to cord care, breast feeding and thermal care in rural setting of Nepal and to observe relationship between socio-demographic, antenatal and delivery care factors with these new born practices.

\section{MATERIALS AND METHODS}

This is a community based descriptive cross-sectional study of quantitative method. It was conducted in rural setting of Nawalparasi district of Nepal. The sample size was determined by using proportion of home deliveries $(73.83 \%)$ according to the annual report 2009/10 of Department of Health Services (DoHS), Nepal. Altogether 296 mothers having less four months child were interviewed between January to June 2011 with well trained six enumerators having qualification of auxiliary nurse midwife working as volunteers in various primary health care institutions. Data were collected from PHC outreach and immunization clinics of eight randomly selected village development committees on socio-demographic, antenatal, delivery and newborn care practices. Three dependent variables (safe cord care, early breast feeding and delayed bathing) and ten sociodemographic, antenatal and delivery care factors (age of mother, birth order, ethnicity, mother's education, family income, antenatal visit, antenatal counseling on newborn care, place of delivery and person assisted during delivery) were determined as independent variables to examine the association between these variables. Safe cord care for this study includes cutting umbilical cord with clean instrument, tying with clean thread and applying nothing in cord stump. Early initiation of breast feeding includes initiation of breast feeding within one hour of birth. Similarly delayed bathing for this study includes bathing newborn baby after 24 hours of birth. Data were analyzed by using SPSS 17.0 and chi squire tests were performed to compare the levels of each of the three care practices with in the socio-demographic, antenatal and delivery care categories with $95 \%$ confidence level for statistical analysis and interpretation.

\section{RESULTS}

Levels of socio-demographic characteristics of the study population are presented in table 1. Majority of the study population were of age group 20-35 years $(79.66 \%)$ and Hindus (93.58\%) with ethnic group Disadvantaged Janajati (50.70\%). Very few respondents were (13.51\%) illiterate. More than half newborn were male with birth order two or more.

Programmatic characteristics are presented in table 2. About two-third $(65.54 \%)$ women received antenatal service four times or above. Less than one-third $(29.05 \%)$ women received counseling on essential newborn care practices during pregnancy. More than half (53.3\%) women were delivered in home to give birth their recent baby and most of these deliveries were conducted by family member and neighbor or the traditional birth attendances. Clean home delivery kit was used only in one-third (32.91\%) home deliveries.

Levels of the selected newborn care practices are presented in table 3. Clean sterile instrument was used in less than half (48.31\%) deliveries to cut the umbilical cord. New unused razor blade was used in half $(50.67 \%)$ of the deliveries. Surprisingly, in three cases, knife and grass cutter was used to cut the umbilical cord. Although clean cord tie were practiced in more than half deliveries (58.78\%) but clean cord keeping practice was practiced one in every four deliveries. In about $3 / 4^{\text {th }}$ deliveries various materials including ash, oil, oil and turmeric and medical drugs and powder was applied in cord stump. The levels of breast feeding practices were 
Kaphle et. al. Newborn Care Practices in Rural Communities of...... JHAS, 2013, Vol. 3, No. 1 P 35-39

cooperatively better than safe cord care practices. Only in about half deliveries (51.35\%) breast feeding was started within one hour of birth. Colostrums feeding were practiced in majority of cases but prelactal feeding was practiced in about $1 / 3^{\text {rd }}$ deliveries. In thermal care, the proportion of immediate drying and wrapping of newborn babies was found to be similar. Delayed bathing (i.e. bathing after 24 hours of birth) was also not much more different from early drying \& wrapping of newborn baby.

Comparison of clean cord care, early breast feeding and delayed bathing practices with socio-demographic factors are presented in table 4. Maternal age was found to be not associated with all three care practices while ethnicity and maternal education was found to be associated with all three care practices.

Table 1: Socio demographic characteristics of study populations $(n=296)$

\begin{tabular}{|c|c|c|}
\hline Characteristics & Frequency & Percentage \\
\hline \multicolumn{3}{|l|}{ Maternal Age } \\
\hline$<20$ years & 49 & 16.66 \\
\hline 20-35 years & 235 & 79.39 \\
\hline 35 or above & 12 & 04.05 \\
\hline \multicolumn{3}{|l|}{ Birth Order of the newborn } \\
\hline First & 135 & 45.61 \\
\hline Second and Above & 161 & 54.39 \\
\hline \multicolumn{3}{|l|}{ Sex of the baby } \\
\hline Male & 161 & 54.39 \\
\hline Female & 135 & 45.61 \\
\hline \multicolumn{3}{|l|}{ Caste/ ethnicity } \\
\hline Dalit & 50 & 16.9 \\
\hline Disadvantaged Janajati & 150 & 50.7 \\
\hline Advantaged Janajati & 34 & 11.5 \\
\hline Upper caste group & 62 & 20.9 \\
\hline \multicolumn{3}{|l|}{ Religion } \\
\hline Hindus & 277 & 93.58 \\
\hline Buddhist & 10 & 03.38 \\
\hline Christian & 9 & 03.04 \\
\hline \multicolumn{3}{|l|}{ Maternal Education } \\
\hline Illiterate & 40 & 13.51 \\
\hline Primary & 69 & 23.31 \\
\hline Secondary & 152 & 51.35 \\
\hline Above secondary & 35 & 11.82 \\
\hline \multicolumn{3}{|l|}{$\begin{array}{l}\text { Monthly Income (Nepalese } \\
\text { currency) }\end{array}$} \\
\hline Below 2250 & 84 & 28.39 \\
\hline $2250-4499$ & 24 & 08.11 \\
\hline 4500 or above & 188 & 63.50 \\
\hline
\end{tabular}

Table 2: Programmatic characteristics of study populations $(\mathbf{n}=\mathbf{2 9 6})$

\begin{tabular}{|l|c|c|}
\hline Characteristics & Frequency & Percentage \\
\hline Antenatal Checkup & & \\
\hline None & 50 & 16.89 \\
\hline At least one & 15 & 05.06 \\
\hline $2-3$ & 37 & 12.50 \\
\hline 4 or above & 194 & 65.54 \\
\hline Counseling on newborn care & & \\
\hline Yes & 86 & 29.05 \\
\hline No & 212 & 70.95 \\
\hline Place of delivery & & \\
\hline Home & 158 & 53.38 \\
\hline Health institutions & 138 & 46.62 \\
\hline Birth attendant & & \\
\hline Family/neighbors & 87 & 29.39 \\
\hline TBAs & 69 & 23.31 \\
\hline Health Workers & 140 & 47.28 \\
\hline
\end{tabular}

Table 3: Selected newborn care practices of study populations

\begin{tabular}{|l|c|c|}
\hline Characteristics & Frequency & Percentage \\
\hline Safe cord care practice & & \\
\hline Sterile instrument for cord cutting & 143 & 48.31 \\
\hline Clean cord tie & 174 & 58.78 \\
\hline $\begin{array}{l}\text { Safe cord keeping without applying } \\
\text { anything }\end{array}$ & 76 & 25.70 \\
\hline Breast feeding practice & 152 & 51.35 \\
\hline Early initiation within one hour & 92 & 31.08 \\
\hline Prelactal feeding & 268 & 90.54 \\
\hline Colostrum feeding & 288 & 77.0 \\
\hline Exclusive feeding unto 1 months of age & & \\
\hline Thermal care practice & 171 & 57.77 \\
\hline Immediate drying of newborn & 170 & 57.43 \\
\hline Immediate wrapping newborn & 152 & 51.35 \\
\hline $\begin{array}{l}\text { Separate Clean clothes for drying and } \\
\text { wrapping }\end{array}$ & 173 & 58.45 \\
\hline Delayed bathing of newborn & & \\
\hline
\end{tabular}

Comparison of clean cord care, early breast feeding and delayed bathing practices with antenatal and delivery care factors are presented in table 5. All the programmatic factors are found to be highly associated with all three care practices. 
Table 4: Comparison of newborn care practices with socio demographic factors

\begin{tabular}{|c|c|c|c|c|c|c|c|c|c|c|}
\hline \multirow{2}{*}{ Characteristics } & \multirow{2}{*}{$\mathrm{N}$} & \multicolumn{3}{|c|}{ Cord care practice } & \multicolumn{3}{|c|}{$\begin{array}{l}\text { Initiation of breast } \\
\text { feeding }\end{array}$} & \multicolumn{3}{|c|}{ Bathing practice } \\
\hline & & $\begin{array}{c}\text { Safe } \\
\%\end{array}$ & \begin{tabular}{c|c} 
Unsafe \\
$\%$
\end{tabular} & P-value & $\begin{array}{c}\text { Early } \\
\%\end{array}$ & \begin{tabular}{|c|} 
Late \\
$\%$ \\
\end{tabular} & P-value & $\begin{array}{r}\text { Before } \\
24 \mathrm{rs} \% \\
\end{array}$ & $\begin{array}{c}\text { After } 24 \\
\text { hrs } \% \\
\end{array}$ & P-value \\
\hline \multicolumn{11}{|l|}{ Maternal age } \\
\hline$<20$ years & 49 & 36.7 & 63.3 & 0.071 & 44.9 & 55.1 & 0.089 & 61.2 & 38.8 & 0.453 \\
\hline $20-35$ years & 235 & 24.3 & 75.7 & & 54.0 & 46.0 & & 59.1 & 40.9 & \\
\hline 35 or above & 12 & 8.3 & 91.7 & & 25.0 & 75.0 & & 41.7 & 58.3 & \\
\hline \multicolumn{11}{|l|}{ Birth order } \\
\hline First & 135 & 32.6 & 67.4 & 0.013 & 51.4 & 48.6 & 0.391 & 33.3 & 66.7 & 0.012 \\
\hline Second \& above & 161 & 19.9 & 80.1 & & 49.1 & 50.9 & & 47.8 & 52.2 & \\
\hline \multicolumn{11}{|l|}{ Sex of newborn } \\
\hline Male & 161 & 21.1 & 78.9 & 0.050 & 49.7 & 50.3 & 0.532 & 41.6 & 58.4 & 0.879 \\
\hline Female & 135 & 31.1 & 68.9 & & 53.3 & 46.7 & & 40.7 & 59.3 & \\
\hline \multicolumn{11}{|l|}{ Caste/Ethnicity } \\
\hline Dalit & 50 & 22.0 & 78.0 & 0.001 & 42.0 & 58.0 & 0.004 & 56.0 & 44.0 & 0.001 \\
\hline Disadvantaged Janajati & 150 & 15.3 & 84.7 & & 48.0 & 52.0 & & 50.7 & 49.3 & \\
\hline Advantaged Janajati & 34 & 58.8 & 41.2 & & 79.4 & 20.6 & & 58.8 & 41.2 & \\
\hline Upper caste group & 62 & 35.5 & 64.5 & & 51.6 & 48.4 & & 80.6 & 119.4 & \\
\hline \multicolumn{11}{|l|}{ Maternal education } \\
\hline Illiterate & 40 & 15.0 & 85.0 & 0.057 & 27.5 & 72.5 & 0.001 & 27.5 & 72.5 & 0.000 \\
\hline Primary & 69 & 30.4 & 69.6 & & 42.0 & 58.0 & & 49.3 & 50.7 & \\
\hline Secondary & 152 & 23.0 & 77.0 & & 58.6 & 41.4 & & 65.1 & 34.9 & \\
\hline Above secondary & 35 & 40.0 & 60.0 & & 65.7 & 34.3 & & 85.7 & 14.3 & \\
\hline \multicolumn{11}{|l|}{ Family income/mths } \\
\hline Below NRs 2250 & 84 & 41.7 & 58.3 & 0.001 & 47.6 & 52.4 & 0.202 & 58.3 & 41.7 & 0.076 \\
\hline NRs 2250-4499 & 24 & 29.2 & 70.8 & & 37.5 & 62.5 & & 37.5 & 62.5 & \\
\hline NRs 4500 and above & 188 & 18.1 & 81.9 & & 54.8 & 45.2 & & 61.7 & 38.3 & \\
\hline
\end{tabular}

Table 5: Comparison of antenatal and delivery care factors and newborn care practices

\begin{tabular}{|c|c|c|c|c|c|c|c|c|c|c|}
\hline \multirow[t]{2}{*}{ Characteristics } & \multirow[t]{2}{*}{$\mathrm{N}$} & \multicolumn{3}{|c|}{ Cord care practice } & \multicolumn{3}{|c|}{$\begin{array}{l}\text { Initiation of breast } \\
\text { feeding }\end{array}$} & \multicolumn{3}{|c|}{ Bathing practice } \\
\hline & & $\begin{array}{c}\text { Safe } \\
\%\end{array}$ & $\begin{array}{c}\text { Unsafe } \\
\%\end{array}$ & P-value & $\begin{array}{c}\text { Early } \\
\%\end{array}$ & $\begin{array}{c}\text { Late } \\
\%\end{array}$ & P-value & $\begin{array}{c}\text { Before } \\
24 \text { hrs } \%\end{array}$ & $\begin{array}{c}\text { After } 24 \\
\text { hrs } \%\end{array}$ & P-value \\
\hline \multicolumn{11}{|l|}{ Antenatal Checkup } \\
\hline None & 50 & 16.0 & 84.0 & 0.014 & 8.0 & 92.0 & 0.001 & 18.0 & 82.0 & 0.001 \\
\hline At least one & 15 & 46.7 & 53.3 & & 33.3 & 66.7 & & 33.3 & 66.7 & \\
\hline $2-3$ & 37 & 40.5 & 59.5 & & 73.0 & 27.0 & & 56.8 & 43.2 & \\
\hline$>3$ & 194 & 23.7 & 76.3 & & 59.8 & 40.2 & & 71.6 & 28.4 & \\
\hline \multicolumn{11}{|c|}{ Counseling on newborn care } \\
\hline Yes & 86 & 45.3 & 54.7 & 0.001 & 66.3 & 33.7 & 0.001 & 74.4 & 25.6 & 0.001 \\
\hline No & 212 & 17.6 & 82.4 & & 45.2 & 54.8 & & 52.4 & 47.6 & \\
\hline \multicolumn{11}{|l|}{ Place of delivery } \\
\hline Home & 158 & 18.4 & 81.6 & 0.002 & 25.3 & 74.7 & 0.001 & 34.8 & 65.2 & 0.001 \\
\hline Health care institution & 138 & 34.1 & 65.9 & & 81.2 & 18.8 & & 82.2 & 17.8 & \\
\hline \multicolumn{11}{|l|}{ Birth attendance } \\
\hline Family/neighbor & 87 & 19.9 & 80.1 & 0.001 & 13.8 & 86.2 & 0.001 & 21.8 & 78.2 & 0.001 \\
\hline Untrained TBA & 46 & 4.3 & 95.7 & & 17.4 & 82.6 & & 23.9 & 76.1 & \\
\hline Trained TBA & 23 & 43.5 & 56.5 & & 73.9 & 26.1 & & 91.3 & 8.7 & \\
\hline Health Workers & 140 & 33.6 & 66.4 & & 82.1 & 17.9 & & 87.9 & 12.1 & \\
\hline
\end{tabular}

\section{DISCUSSION:}

This study has described three essential newborn care practices in rural setting where most of the deliveries occur at home and examined their association with socio-demographic and programmatic factors.

Clean cord care: Clean cord care is important in preventing early neonatal infections. In this study, most of the women reported clean cord cutting (98.9\%, sterile instrument and new blade or boiled blade) but the clean cord tie was practiced only just above half (58.78\%) of these deliveries and the safe cord keeping was only one-fourth $(25.7 \%)$. Low level of clean cord tie was due the less use of clean home delivery kit in home deliveries (32.91\% out of 158 home deliveries) and low level of safe cord keeping practice was due to application of various substances such as mustard oil, a mixture of mustard oil and turmeric, ash, sindoor and powders and the ointments. Application of various substances in the cord stumps was also found to be common in institutional deliveries after discharge from the health facilities. Cord cutting, tying and safe cord keeping practice have been identified as risk factors for neonatal infection ${ }^{13-18}$ and the studies suggests low coverage in South Asia. ${ }^{19-21}$ The study presented here suggests the need increase the community awareness through the community level health workers and birth attendants to keep cord stump clean and dry without applying anything even the discharge from hospitals and birth centers. Study conducted on home delivery and newborn care practice in Western Nepal also supports the low use of clean home delivery kit. ${ }^{22}$

Early Initiation of breast feeding: Early initiation of breast feeding is vital for neonatal health and Survival. Nationally, in 1996 only $18.2 \%$ of the women breastfed their babies within an hour of birth which increased to $35.4 \%$ in 2006 and 44.5 $\%$ in $2011 .^{6-8}$ In this study early initiation of breast feeding as soon as possible within one hour of delivery was found in $51.35 \%$ deliveries. However finding from present study compare poorly with recent studies from the neighboring countries (Pakistan and Bangladesh as 91\%, 73\% and >70\% respectively). ${ }^{21,23,24}$ Despite the remarkable increase in the proportion of women breastfeeding their babies during the first hour of birth over the twenty year period, the coverage is still not satisfactory. Prelectal feeding and colostrum feeding practice found in this study is not much more different from earlier studies conducted in Nepal. ${ }^{22}$ Maternal Education, antenatal checks up, antenatal counseling on newborn care, place of delivery and person assisted during delivery found to be associated with early initiation of breast feeding. The relationship between the maternal education and improved newborn care has been demonstrated by earlier studies. ${ }^{25,26}$

Delayed Bathing: Bathing newborn baby after 24 hours of birth is regarded as delayed bathing. Bathing babies early can increase the risk of hypothermia and if the baby is of low birth weight the risk is even greater. Hypothermia is one of the major causes of mortality among newborns. In Nepal, bathing a baby soon after birth is widely prevalent because the baby's body is coated with vernix, which is considered dirty. Therefore, bathing a baby soon is a custom followed to purify the baby. Usually, babies are bathed with lukewarm water after cord cutting and cleaning the spot within half to one hour of duration. Breastfeeding is also not initiated until the baby is bathed. ${ }^{10}$ Nationally only $9.3 \%$ of the babies were bathed after 24 hours of birth 2006 and $26.1 \%$ in $2011 .^{7,8}$ In this study bathing newborn baby at least after 24 hours of born was found $58.45 \%$ which is more than double of finding of NDHS $2011^{8}$ however it is not still satisfactory. Maternal education and all the programmatic factors were found to be highly associated with delayed bathing practice. So the study suggests need to increase the coverage of maternal and newborn care services. 


\section{CONCLUSION}

High-risk home delivery and newborn care practices are still common in rural population of Nepal. In-depth qualitative studies are needed to explore the reasons for poor newborn care practices. Community-based interventions are required to improve the new born care practices in community level.
The high-risk traditional newborn care practices like unsafe cord care, delayed breast feeding, early bathing, pre-lacteal feeding and discarding colostrum need to be addressed by community-based health education and awareness programmes.

\section{ACKNOWLEDGEMENT}

We express our sincere thanks to Prof. Nabin Kumar Shrestha and Prof. Dr. Keshav Parajuli for the valuable guidance and support. We are also grateful to Prof. Dr. Bishnuraj Tiwari and Associate Prof. Dr. Nirmala Jamarkattel for providing the grant and academic support. The authors also thank all the mothers who participated in the study.

\section{REFERENCES}

1. World Health Organization. Perinatal mortality: a listing of available information. FRH/MSM.96.7. WHO, Geneva; 1996.

2. SNL. States of Worlds New born care. Washington DC. Save the children federation USA; 2001.

3. Tinker A, Hoope Bender P, Azfar S, Bustreo F, Bell R. A continuum of care to save new born lives. Lancet. 2005; 365:822-65.

4. Lawn JE, Cousens S, Zupan J. Four million neonatal deaths: Where? When? Why?. Lencet. 2005; 365(9462):891-900.

5. Bryce J, Boschi P, Shibuya K, Black RE. WHO estimates of the causes of deaths in children. Lencet. 2005 ; 365 (9465):1147-52.

6. Ministry of Health [Nepal], New ERA \& Macro International Inc. Nepal Family Health Survey 1996. Kathmandu, Nepal: Ministry of Health and Population, New ERA and Macro International Inc.1997.

7. Ministry of Health and Population, Nepal, New ERA \& Macro International Inc. Nepal Demographic and Health Survey 2006. Kathmandu, Nepal: Ministry of Health and Population, New ERA and Macro International Inc. 2007.

8. Ministry of Health and Population, Nepal, New ERA, Macro International Inc and USAID. Nepal Demographic and Health Survey 2011, preliminary report. Kathmandu, Nepal: Ministry of Health and Population, New ERA, Macro International Inc. and U.S. Agency for International Development. August 2011.

9. Department of Health Services. Annual Report 2009/10. Department of Health Services. Ministry of Health and Population, Nepal. 2010.

10. Gurung G. Practices on immediate care of newborn in the communities of Kailali district. Nepal Med Coll J. March; 2008; 10(1):41-4.

11. Save Newborn Lives. States of Worlds New born care. Washington DC. Save the children federation USA; 2001.

12. WHO. Essential New born care: A report of technical Working group, Geneva; 1996.

13. Moss W, Darmstadt G, Marsh D, Black R, Santosham M. Research priorities for the reduction of perinatal and neonatal morbidity and mortality in developing country communities. J Perinatol. 2002; 22:484-95.

14. Darmstadt GL, Bhutta ZA, Cousens S, Adam T, Walker N, de Bernis L. Evidence-based, cost-effective interventions: how many newborn babies can we save? Lancet. 2005; 365(9463):977-88.

15. WHO. Care of the umbilical cord: a review of the evidence. Geneva: World Health Organization; 1998.

16. Bhutta Z, Darmstadt G, Ransom E. Using evidence to save newborn lives. Policy brief. Washington, DC: Population Reference Bureau; 2003.

17. Bhutta Z. Effective interventions to reduce neonatal mortality and morbidity from perinatal infection. In Costello A, Manandhar D, eds. Improving newborn infant health in developing countries. London: Imperial College Press; 2000; 289-308.

18. Baqui AH, Williams EK, Darmstadt GL, Kumar V, Kiran TU, Panwar D, Sharma RK, Ahmed S, Sreevasta V, Ahuja R, Santosham M, Black RE. Newborn care in rural Uttar Pradesh. Indian J Pediatr. 2007 Mar; 74(3):241-7. PubMed PMID: 17401262.

19. Manandhar D, Osrin D, Shrestha B, Mesko N, Morrison J, Tumbahangphe K. Effect of participatory intervention with women's groups on birth outcomes in Nepal: cluster-randomised controlled trial. Lancet. 2004; 364(9438):970-979.

20. Nandan D, Mishra S. Delivery Practices in West Uttar Pradesh. Indian J Public Health. 1996; 40(1):20-21.

21. Osrin D, Tumbahangphe K, Shrestha D, Mesko N, Shrestha B, Manandhar M. Cross sectional, community based study of care of newborn infants in Nepal. BMJ. 2002; 325(1063).

22. Chandrasekhar TS, Joshi H, Sreekumaran B, Giri S, Chuni N. Home delivery and newborn care practices among urban women in western Nepal: a questionnaire survey. Women Health Popul. 2006 Aug; 24(7):386-402.

23. Fikree F, Ali T, Durocher J, Rahbar M. Newborn care practices in low socioeconomic status settlements of Karachi, Pakistan. Social Sci Med. 2005; 60:911-921.

24. Holman D, Grimes M. Colostrum Feeding Behavior and Initiation of Breastfeeding in Rural Bangladesh. J Biosoc Sci. $2001 ; 33: 139-154$.

25. Caldwell J, McDonald P. Influence of maternal education on infant and child mortality: levels and causes. Health Policy Educ. 1982; 2:251-267.

26. Mosley W, Chen L. An analytical framework for the study of child survival in developing countries. Population and Development Review 1984; Suppl. (10):25-45. 